\title{
The development of an attract-and-kill bait for controlling the small hive beetle (Coleoptera: Nitidulidae)
}

\author{
Charles J. STUHL \\ Center for Medical, Agricultural and Veterinary Entomology, USDA-ARS, 1700 SW 23rd Dr., Gainesville, FL 32608, \\ USA
}

Received 29 March 2019 - Revised 30 September 2019 - Accepted 11 December 2019

\begin{abstract}
This research investigates the development of an attract-and-kill bait for in-hive control of the small hive beetle, Aethina tumida. The control method employs attracting the beetles to an in-hive trap with a feeding attractant/stimulant where a toxicant is delivered by consuming an edible bait. Investigations into mild insecticides led to the use of boric acid. At low doses, boric acid is non-toxic to humans but lethal to insects. This research was designed to identify key compounds that would attract small hive beetles, develop an edible bait using those compounds and if the diet would be consumed by the beetle, determine the lethal dose with the lowest amount of toxicant, and the effects the toxicant would have on the honey bee. Attractive compounds were identified from honey bee pollen patties inoculated Kodamaea ohmeri yeast and resulted in the identification of three key components: ethyl propionate, isobutyl propionate, and ethyl butyrate. A diet comprised of corn gluten meal, barley flour, soy flour, Brewer's yeast, and glycerin containing the attractant/feeding stimulant was highly attractive and readily consumed. In laboratory trials, the treatments containing the attract-and-kill with $2 \%$ boric acid reduced the beetle population to zero within a few days. There was no significant difference between the sex of the beetle for survival on any of the treatments. Honey bee survival was reduced by ingesting the boric acid. The development of an inexpensive small hive beetle trapping system is essential for in-hive control of this devastating pest. This system has the potential to provide beekeepers a tool for control of this pest species that affects honey bee health and survival worldwide.
\end{abstract}

\section{Honey bee pests / Aethina tumida / Apis mellifera}

\section{INTRODUCTION}

The small hive beetle, Aethina tumida, is a major pest of the European honey bee (Apis mellifera L, Hymenoptera: Apidae). First discovered in the USA in 1996, and later confirmed in Florida in 1998. The beetle's current range spans the USA, Canada, Mexico, Jamaica, Australia, and Cuba and confirmed in Italy in 2014 (Ellis and Hepburn 2006; Neumann and Elzen 2004). Small hive beetle adults and larvae cause

Corresponding author: C. Stuhl, charles.stuhl@usda.gov

Manuscript editor: Peter Rosenkranz destruction by consuming honey bee eggs, brood, pollen, and honey (Schmolke 1974; Hepburn and Radloff 1998; Ellis et al. 2002). It has also been demonstrated that the beetle can survive and reproduce on commercial honey bee pollen substitutes (Stuhl 2017). Beetles can live for many months, with female's laying an abundance of eggs in their lifetime. Therefore, the population can grow to uncontrollable levels within a short amount of time (Hood 2004, 2011). Honey and pollen stores are infected with yeast, Kodamaea ohmeri, that is carried in the beetle's gut, causing the honey to ferment and rendering it no longer suitable for consumption (Benda et al. 2008). Weak and queenless hives are more susceptible to SHB damage. When the larval population 
reaches a certain point, the queen will stop egglaying and the colony may abscond from the hive. However, all colonies are susceptible to damage when large numbers of beetles are present.

Before pupation, the larvae leave the hive and pupate in the soil within the vicinity of the hives. The larvae remain 3-6 weeks in the soil to complete their lifecycle. After emergence, adult beetles will seek out a host beehive by utilizing colony odors. The adults are strong fliers and easily disperse among hives. Adults can live many months with overlapping generations within a colony in a single season (Zawislak 2010). The impact this pest has on honey bee survival has made the need for an effective measure to control this invasive pest. There are a few ineffective traps for beetle control. Beetles are captured by chance in these traps only when populations are extremely high. There is no attractant used in luring the beetles to their death. The target strategy of the attract-and-kill system is directed at attracting and exposing the beetle adults to the toxic bait for consumption, thus reducing the population to zero within days. Due to the harmful effects of pesticides on honey bees and the consumption of hive products by humans, this creates a major obstacle for pest management within a hive. Insecticides such as coumaphos have been effective in controlling small hive beetle within the hive (Neumann and Hoffmann 2008; Elzen et al. 1999). The challenge was to find a toxic substance that would kill the beetles, yet non-toxic to humans. Investigations into mild insecticides led to boric acid $\left(\mathrm{H}_{3} \mathrm{BO}_{3}\right)$. When ingested by an insect, boric acid disrupts the cellular lining of the insect's foregut, thus resulting in death. This has been used as an effective toxicant for the control of cockroaches, ants, and silverfish and termites. Boric acid naturally occurs in the environment and can be found in soil, water, and plants (Habesa et al. 2006; Klotz et al. 1996; Boone et al. 2012). The minimal ingested lethal dose of boric acid is $15-20 \mathrm{~g}$ in adults (Health and Human Services 2010). This dosage is one hundred times the amount used in the treatments in this study. Previous research suggests that boric acid is lethal to the small hive beetle (Reyes-Escobar et al. 2015).

Artificial diets have been used to rear multiple species of Nitidulid beetles (Peng and Williams 1990a). Diets for the confused sap beetle, Carpophilus multilatus, a pest of dried figs and the strawberry sap beetle, Stelidotn gemillata, were developed (Peng and Williams 1990b). Additionally, lepidopteran larval diets have been modified to rear Nitidulid beetles (Hall et al. 1978; Dowd 1987). The small hive beetle has been successfully reared in the laboratory on honey, pollen, and brood (Neumann et al. 2001).

An attractant must be used to lure the beetles into a trap. Many sap beetles are attracted to damaged, overripe, or decomposing vegetables and fruits. Hive odors act as an attractant for the small hive beetle to locate a hive to infest (Suazo et al. 2003). For research purposes, small hive beetles were laboratory reared in large numbers and fed on commercially manufactured pollen dough patties. The patties are mixed with Kodamaea ohmeri yeast that was isolated from the beetle's gut, grown on agar media and freezedried. After a 30-day period, pollen dough becomes fermented and extremely attractive to the beetle (Arbogast et al. 2003). Adult beetles feed and reproduce on the patty diet, and complete larval development. Volatile organic compounds produced by the fermented pollen dough were evaluated as an attractant and feeding stimulant to be used in the attract-and-kill bait. Attractive odors have been isolated for the dusky sap beetle, Carpophilus lugubris; volatiles emitted from whole-wheat bread dough inoculated with baker's yeast were isolated and found to be attractive (Lin and Phelan 1991). The devastating effects the small hive beetle has on managed honey bees warranted the investigation into the use of an attract-and-kill trapping system. The aim of this research was to develop an effective, low-cost inhive control measure for the small hive beetle.

\section{MATERIALS AND METHODS}

\subsection{Source of beetles}

Aethina tumida had been in colony for two generations, having been collected from wild 
populations. Beetles were collected from honey bee hives maintained at the USDA-ARS, Center for Medical, Agricultural and Veterinary Entomology (USDA-ARS, CMAVE), Gainesville, FL, USA. All beetles were reared on pollen dough (Global Patties, Butte, MT) inoculated with Kodamaea ohmeri yeast. The yeast was collected from adult beetles, cultured on yeast extract peptone dextrose (YPD) agar plates, and freeze-dried for later use. Insects were reared in a temperaturecontrolled chamber at $23 \pm 5{ }^{\circ} \mathrm{C}, 60 \% \mathrm{RH}$, and photoperiod of 12:12 (L: D) h. Adult beetles used in the assay were newly emerged and provided with water.

\subsection{Diet formulation}

Cereal grains were chosen to be evaluated as the ingredients for the preparation of the edible bait. Corn gluten meal (Boer Commodities, Fresno, CA); barley flour (Honeyville, Rancho Cucamonga, CA), soy flour (Cargill, Inc., Minneapolis, MN), and Brewer's yeast (International Ingredient Corp., St. Louis, MO) were selected as the ingredients to be evaluated. Glycerin was used as a binder and humectant to allow the diet to be pliable for an extended period. Dry ingredients were incorporated with the glycerin using a stand mixer (KitchenAid(C) and blended until the mixture formed stiff dough.

\subsection{Volatile collection}

Volatiles were collected using a headspace collection technique (Heath and Manukian 1992). This technique was used to isolate volatile compounds from the pollen dough inoculated with Kodamaea ohmeri yeast. A sample of the pollen dough was placed in a cylindrical glass volatile collection chamber $(23 \mathrm{~cm}$ tall and $4 \mathrm{~cm}$ outside diameter) (Figure 1). Dry charcoal-filtered air was pushed into one end of the chamber and over sample and exited the chamber via a vacuum system. The air then passed through a volatile collection filter containing $50 \mathrm{mg}$ of Tenax $®$ Porous Polymer Adsorbent (Sigma-Aldrich, USA) for $5 \mathrm{~min}$.

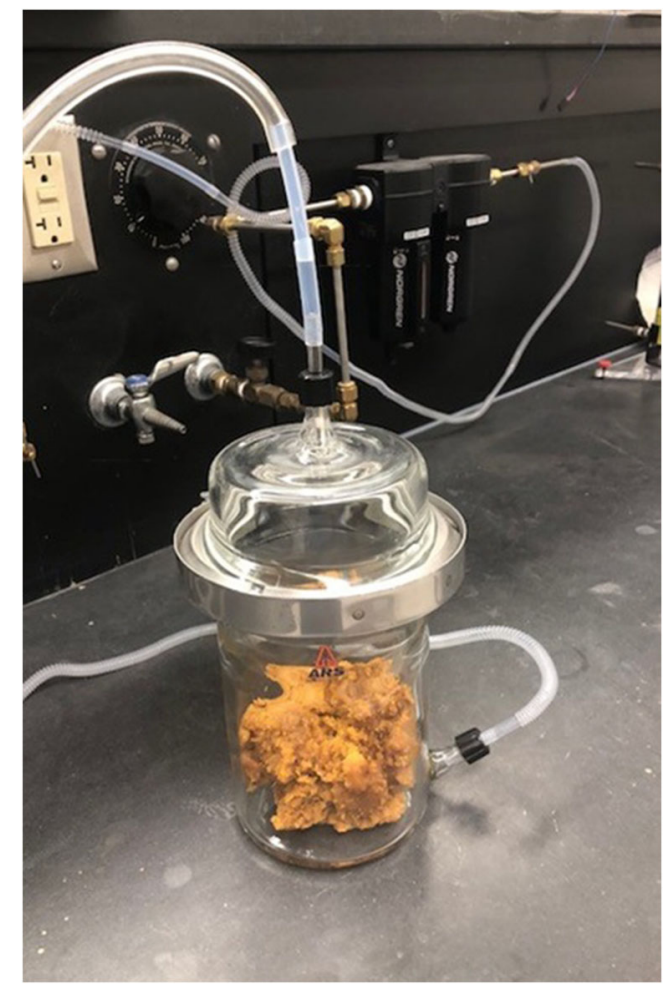

Figure 1. Volatile collection of the pollen dough using a Tenax ${ }^{\circledR}$ filter.

\subsection{Identification of attractant/feeding stimulant}

The volatile compounds collected were analyzed by GC-MS (GC: Hewlett Packard 6890 with an HP-5MS capillary column of $30 \mathrm{~m}$ long, $0.25 \mathrm{~mm}$ inner diameter, and $0.25-\mu \mathrm{m}$ film thickness; MS: Hewlett Packard 5973 mass selective detector, $70 \mathrm{eV}$, equipped with a thermal desorption cold trap injector (TCT) (CP4010; Chrompack, B ergen op Z o om, The Netherlands)). Headspace volatiles collected on Tenax ${ }^{\circledR}$ TA were released from the adsorbent by heating in the TCT at $220^{\circ} \mathrm{C}$ for $8 \mathrm{~min}$ within a flow of helium gas. The desorbed compounds were collected in the TCT cold trap unit (SIL5CB-coated fused silica capillary) at $-130{ }^{\circ} \mathrm{C}$. Flash heating of the cold trap unit injected the compounds into the capillary column of the gas chromatograph to which the cold trap unit was connected. The oven temperature of the 
GC was programmed to rise from $40{ }^{\circ} \mathrm{C}(5-\mathrm{min}$ hold) to $280{ }^{\circ} \mathrm{C}$ at $15{ }^{\circ} \mathrm{C} / \mathrm{min}$. The headspace volatiles were identified by comparing their mass spectra to those of the database (NIST and Department of Chemical Ecology, Göteborg University, Sweden) and by comparing their retention times to those of authentic standards.

\subsection{SHB feeding bioassay}

The assay was developed to (1) determine if the diet would be consumed by the beetle, (2) determine the lethal dose with the lowest amount of toxicant (boric acid), and (3) to determine the effect boric acid would have on the honey bee. The feeding assays were performed in a climatecontrolled chamber at $23 \pm 5{ }^{\circ} \mathrm{C}, 60 \% \mathrm{RH}$, and photoperiod of 12:12 (L: D) h. Treatments were $0.5 \%, 1 \%, 2 \%, 3 \%, 4 \%$, and $5 \%$ boric acid (Bulk Apothecary, Aurora, $\mathrm{OH}$ ) by weight. One set of control beetles was provided with only water and another with diet containing the attractant/feeding stimulant and no toxicant, another with diet containing no attractant/feeding stimulant and no toxicant. To test the preference for the attractant/ feeding stimulant, beetles were provided with diet with no toxicant and no attractant/feeding stimulant. A 5-g ball of diet was placed in a plastic container $(10 \times 10 \times 7.5 \mathrm{~cm})$ with ventilation provided through a fine copper wire grid glued over an 8-cm circular hole in the lid. Ten males and ten female beetles were placed in each container. The assay was checked daily and dead beetles were removed from the assay containers. The assay was run until all beetles died. There were 50 replicates performed for each treatment.

\subsection{Honey bee feeding bioassay}

The assay was performed to measure the effects of the toxicant (boric acid) on honey bee survival. Five worker honey bees were placed in a $10 \times$ $10 \times 7.5 \mathrm{~cm}$ plastic container. Ventilation was provided through a fine copper wire grid glued over an $8-\mathrm{cm}$ circular hole in the lid. A $6 \mathrm{~cm} \times 6 \mathrm{~cm}$ piece of wax foundation (Dadant \& Sons, Hamilton, IL) was adhered to the lid of the container as a resting place for the bees. Each container received two 30-ml soufflé cups (Solo, P100), one with water, the other with the treatment. The treatment consisted of a $10 \%$ sucrose solution containing $2 \%$ by volume boric acid. A $1.5-\mathrm{cm}$ hole was placed in the lid (Solo, ML8) which allowed for a braided cotton dental wick (Richmond Dental, Charlotte, NC) to be inserted and administer the contents of the cup. There were 100 replicates of the treatment and 100 replicates of the control. The assay was performed in a climate-controlled chamber at $23 \pm 5{ }^{\circ} \mathrm{C}, 60 \% \mathrm{RH}$, and photoperiod of 12:12 (L: D) h. Assay was run until all the bees in the treatment died.

\section{STATISTICAL ANALYSES}

Analysis was conducted by using SAS programming (SAS Institute 2009). Analysis of variance (PROC ANOVA) followed by means separation with the Waller test was employed to compare the mean responses to the treatments.

\section{RESULTS}

\subsection{Feeding attractant/stimulant}

Compounds identified from the volatile collection resulted in the identification of three key components: ethyl propionate, isobutyl propionate, and ethyl butyrate. The amounts from the collections were quantified and the proportions needed for addition to the dry ingredients were calculated. The feeding attractant/stimulant was comprised $40 \mu$ l ethyl propionate (Sigma-Aldrich Corp, St. Lois, MO), $2 \mu$ isobutyl propionate (EMD Millipore Corp., Billerica, MA), $2 \mu$ l ethyl butyrate (Sigma-Aldrich Corp, St. Lois, MO) added to $2 \mathrm{ml} 100 \%$ ethyl alcohol (Sigma-Aldrich Corp, St. Lois, MO). The mixture had sweet fermented notes, with a rum-like odor like fermented pollen dough.

\subsection{Diet ingredients}

The most effective composition comprised of $98 \%$ dry ingredients, $2 \%$ by weight of a toxicant, and $30 \%$ by volume glycerin. The diet consisted of two parts corn gluten meal; to one part: barley flour, soy flour, and Brewer's yeast. The toxicant was added at $2 \%$ by weight of the total diet with 
glycerin added as the binder. A 200-g mixture of the diet would contain $80 \mathrm{~g}$ corn gluten meal, $40 \mathrm{~g}$ barley flour, $40 \mathrm{~g}$ brewer's yeast, $4 \mathrm{~g}$ boric acid, and $140 \mathrm{ml}$ glycerin. The attractant/feeding stimulant was added a rate of $2 \mathrm{ml}$ of solution per $200 \mathrm{~g}$ of diet during the mixing process.

\subsection{SHB feeding bioassay}

A comparison between beetles provided with water which survived 4 days and the diet containing the attractant/feeding stimulant and no toxicant survived $<30$ days resulted in a significant difference in survival $(F=175, \mathrm{df}=1, p=<$ 0.0001 ) (Figures 2 and 3 ). The treatment with no attractant/feeding stimulant and no toxicant had a steady decline in death until day 12 when all beetles were dead. Beetles survived 8 days on the treatment containing the $0.5 \%$ boric acid. Treatments that contained $1 \%, 2 \%$, and $3 \%$ boric acid survived 6 days, with the $2 \%$ treatment having an earlier decline in death than the other two treatments. Beetle's survived 5 days on the $4 \%$ and $5 \%$ boric acid treatments. Beetles fed on the

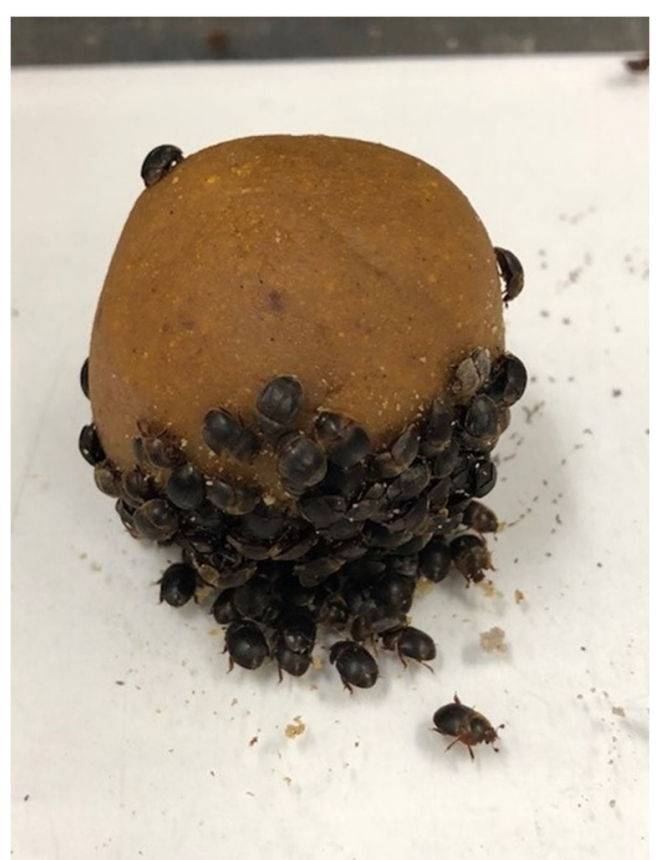

Figure 2. Small hive beetles actively feeding on the attract-and-kill bait containing $2 \%$ boric acid. diet immediately after exposure (Figure 2). There was no significant difference between the sex of the beetle for survival on any of the treatments.

\subsection{Honey bee feeding bioassay}

Honey bees that were fed a $10 \%$ sucrose solution survived for 10 days (Figure 4). Bees that received the treatment of $10 \%$ sucrose solution with $2 \%$ boric acid survived for 3 days.

\section{DISCUSSION}

This study demonstrated that the small hive beetle will consume an artificial diet composed of corn gluten meal, barley flour, soy flour, Brewer's yeast, and glycerin. If the diet contains $2 \%$ or less boric acid, the beetles will readily feed and die shortly thereafter. Survival was greater on the treatments that contained the attractant/feeding stimulant and no toxicant. The attractant/feeding stimulant mimics the odor associated with fermentation of the pollen patty from the yeast introduced into the hive by adult beetles. This low-cost additive appears to be essential to get high numbers of beetles feeding and faster population reduction. Beetles provided with water survived 4 days, while the control that contained diet with no toxicant survived greater than 30 days. Acceptance of the diet was further confirmed when eggs and larvae were seen on the treatment containing the attractant/feeding stimulant and no toxicant after a few days. None of the other treatments showed any signs of egg laying or larvae. The 4 and 5\% treatments appeared to deliver the fastest death, however, there were no signs that the diet was being consumed by the beetles. Therefore, the beetles died from starvation. Beetles survived 8 days on the treatment containing the $0.5 \%$ boric acid. This amount of toxicant is lethal; however, it takes longer for beetle mortality compared to other treatments. Earlier death (6 days) was seen on treatments that contained $1 \%, 2 \%$, and $3 \%$ treatments. The $2 \%$ treatment had an earlier decline, with $50 \%$ death in 3 days. This proved to be the best dosage of toxicant to pursue. Therefore, the $2 \%$ treatment was selected to test its effects on the honey bee. Honey bee survival was 11 days on the treatments without the toxicant and survival on 


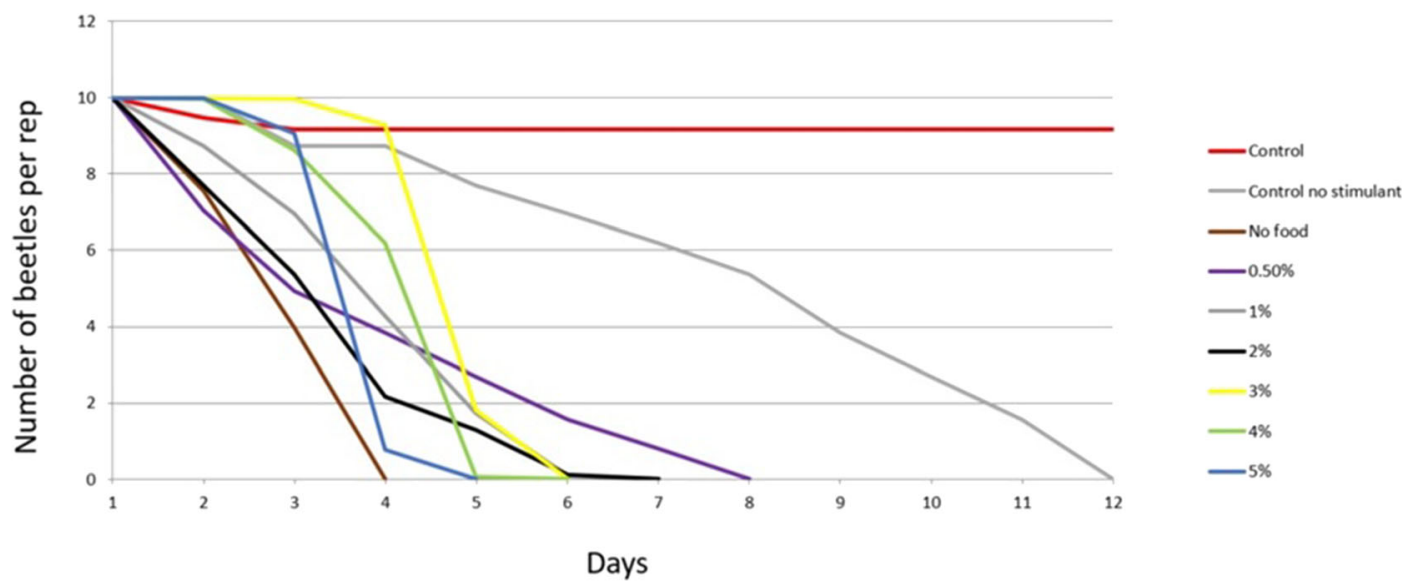

Figure 3 . Mean number of days survival of adult Aethina tumida males and females on varying attract-and-kill baits and controls $(n=9000)$.

treatments containing the toxicant was 4 days. Results confirmed that the boric acid is lethal to the honey bee. Fortunately, the size of the beetle would permit a trap that would only allow for beetle access. The placement of a low-profile trap in areas of high beetle aggregation would provide beetle access to the bait while limiting honey bees. Due to the frailty of the honey bee and its brood, it is not possible to apply an insecticide within the hive. Insecticide use is also a concern when hive products are used for human consumption. Additionally, invertebrates develop resistance over

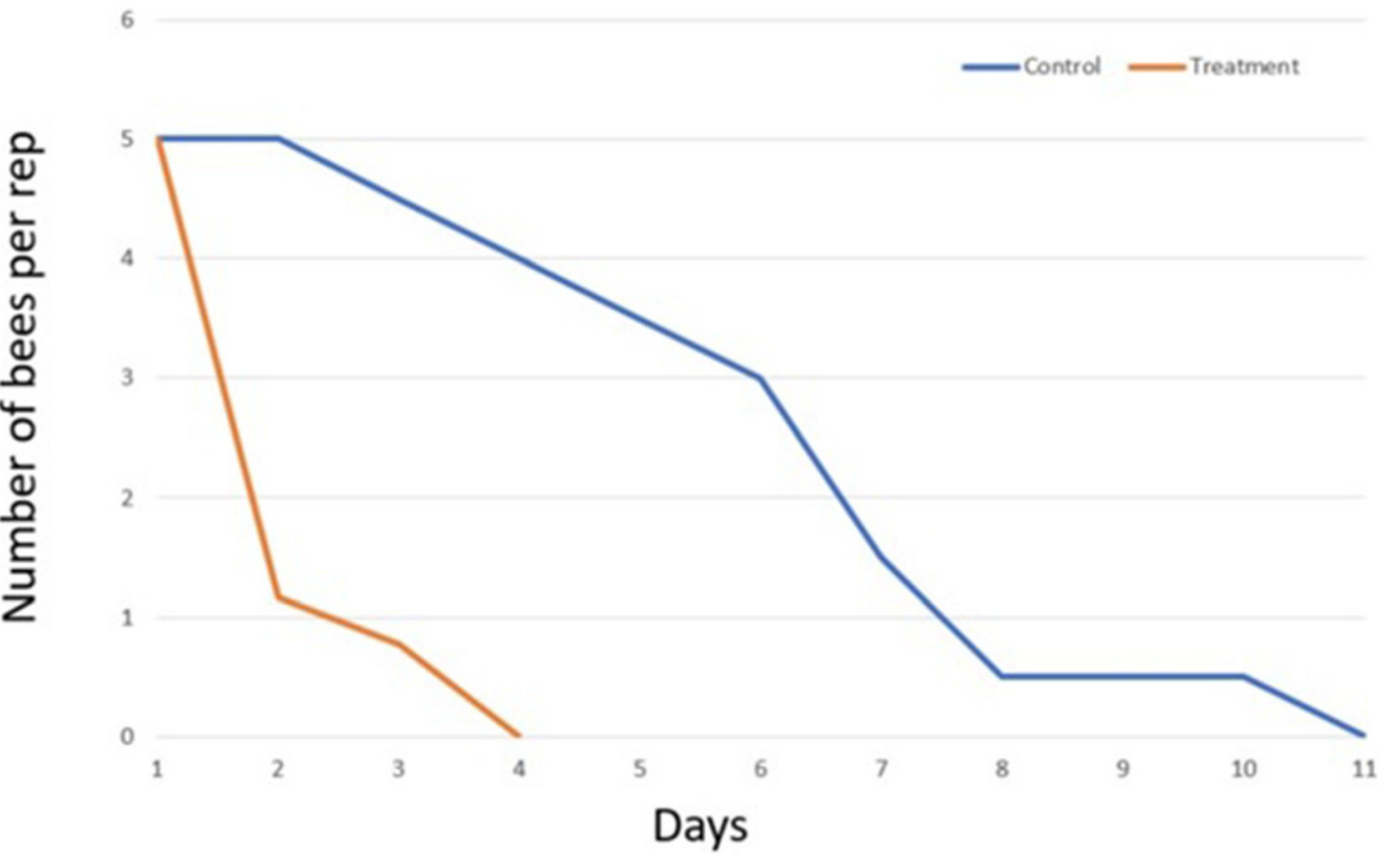

Figure 4 . Mean number of days survival of worker honey bees, Apis mellifera, on a $2 \%$ boric acid sugar solution compared to a control $(n=1000)$. 
time. Varroa destructor has shown signs of resistance to the organophosphorus acaricide coumaphos (Spreafico et al. 2001). Baited traps have proven useful in control and monitoring of other Nitidulid beetle populations (Lin and Phelan 1991). As stated, there is no effective attractantbased in-hive control measure for the small hive beetle. An effective attract-and-kill method of control is essential for the survival of the honey bee. Current in-hive control methods rely on the chance that a beetle will fall into the trap; with no proven attractant associated with capture. An edible diet comprised of bulk recourses enables the manufacturer to produce the bait at a low cost. The hiding and aggregation behavior of the beetle can be exploited. The placement of a low-profile trap that excludes the honey be from entering would be the best delivery method. A commercially manufactured disposable plastic trap that is prebaited is the end goal of this research. This control measure, in conjunction with cultural practices, may offer relief from this invasive pest.

Additional research needs to be performed as to the effectiveness and the best placement within a hive for this attract-and-kill system. This in-hive low-cost control measure far surpasses the replacement cost of an entire hive. If the small hive beetle is present within an apiary, there is a good chance that every hive at that location is infested. Additionally, the placement of the attract-and-kill as a preventative measure within every hive will ensure all hives are protected. This technology will offer beekeepers a method of control for the small hive beetle that is affecting this agricultural commodity throughout the world.

\section{AUTHOR CONTRIBUTIONS}

CS conceived, designed, and wrote the manuscript.

Mise au point d'un appât mortel pour lutter contre le petit coléoptère des ruches (Coleoptera : Nitidulidae).

ravageurs des abeilles / Aethina tumida / Apis mellifera .
Die Entwicklung eines Attraktions-Tötungs-Köders für die Kontrolle des Kleinen Beutenkäfers (Coleoptera: Nitidulidae)

\section{Honigbienenschädlinge / Aethina tumida / Apis mellifera}

\section{REFERENCES}

Arbogast, R.T., Torto, B., Van Engelsdorp, D., Teal, P.E. (2003) An effective trap and bait combination for monitoring the small hive beetle, Aethina tumida (Coleoptera: Nitidulidae). Fla. Entomol. 90 (2), 404-6

Benda, N.D., Boucias, D., Torto, B., Teal P.E. (2008) Detection and characterization of Kodamaea ohmeri associated with small hive beetle Aethina tumida infesting honey bee hives. J. Apicult. Res. 47(3), 94 201

Boone, C.; Bond, C., Stone, D. (2012) Boric acid general fact sheet; National Pesticide Information Center, Oregon State University Extension Services. http://npic. orst.edu/factsheets/boricgen.html (accesses on 04 March 19)

Dowd, P.F. (1987) A labor-saving method for rearing the dried fruit beetle (Coleoptera: Nitidulidae) on pinto bean-based diet. J. Econ. Entomol. 80, 1351-1353

Ellis, J.D., Hepburn, H.R. (2006). An ecological digest of the small hive beetle (Aethina tumida), a symbiont in honey bee colonies (Apis mellifera). Insect. Soc. 53, 8-19

Ellis, J.D., Neumann, P., Hepburn, H.R., Elzen, P.J. (2002) Longevity and reproductive success of Aethina tumida (Coleoptera: Nitidulidae) fed different natural diets. J. Econ. Entomol. 95, 902-907

Elzen P.J., Baxter, J.R., Westervelt, D., Randall, C., Delaplane, K.S., Cutts, L., Wilson, W.T. (1999) Field control and biology studies of a new pest species, Aethina tumida Murray (Coleoptera, Nitidulidae) attacking European honey bees in the Western hemisphere. Apidologie 30, 361-366

Habesa, D., Morakchia, S., Aribia, N., Farineb, J.P., Soltania, N. (2006) Boric acid toxicity to the German cockroach, Blattella germanica: alterations in midgut structure, and acetylcholinesterase and glutathione Stransferase activity. Pestic. Biochem. Phys. 84(1), 1724

Hall, R.W., Smilanick, J.M., Ehler, L.E. (1978) Laboratory rearing and field observations on Carpophilus mutilatus. Ann. Entomol. Soc. Am. 71, 408-410

Health and Human Services, Public Health Service, Agency for Toxic Substances and Disease Registry. 2010 Toxicological profile for boron, pp. 11

Heath, R. R., Manukian, A. (1992). Development and evaluation of systems to collect volatile 
semiochemicals from insects and plants using a charcoal-infused medium for air purification. J. Chem. Eco. 18(7), 1209-1226

Hepburn, H.R. and Radloff, S.E., (1998) Honeybees of Africa. Springer Science \& Business Media Berlin

Hood, W.M. (2004) The small hive beetle, Aethina tumida: a review. Bee World 85, 51-59

Hood, W.M. (2011) Handbook of small hive beetle IPM. Clemson University Cooperative Extension Program. Extension Bulletin 160

Klotz, J., Oi, D., Vail, K.M., Williams, D. (1996) Laboratory evaluation of a boric acid liquid bait on colonies of Tapinoma melanocephalum Argentine ants and Pharaoh ants (Hymenoptera: Formicidae), J. Econ. Entomol. 89(3), 673-677

Lin, H., Phelan, P.L. (1991) Identification of food volatiles attractive to dusky sap beetle, Carpophilus lugubris (Coleoptera: Nitidulidae). J. Chem. Eco. 17(6),12731286

Neumann, P, Elzen, P.J. (2004) The biology of the small hive beetle (Aethina tumida, Coleoptera: Nitidulidae): gaps in our knowledge of an invasive species. Apidologie 35, 229-247

Neumann, P., Hoffmann, D. (2008) Small hive beetle diagnosis and control in naturally infested honeybee colonies using bottom board traps and CheckMite + strips. J. Pest Sci. 81(1), 43

Neumann, P., Pirk, C.W., Hepburn, H.R., Elzen, P.J., Baxter, J.R. (2001) Laboratory rearing of Aethina tumida (Coleoptera,Nitidulidae). J. Apicult. Res. 40, 111-112

Peng, C., Williams, R.N. (1990a) Artificial diet for the strawberry sap beetle, Stelidota geminata (Say) (Nitidulidae: Coleoptera). J. Agr. Entomol. 7(2),137140
Peng, C. Williams, R.N. (1990b) Multiple-species rearing diet for sap beetles (Coleoptera: Nitidulidae), Ann. Entomol. Soc. Am. 83(6) 1155-1157

Reyes-Escobar, O., Dosal-Alonso, E., Lara-Alvarez, C., Lara-Alvarez, L.G., Dorantes-Ugalde, J.A., SaldañaLoza, L.M., (2015) Lethal effect of boric acid and attractants against the small hive beetle, Aethina tumida Murray (Coleoptera: Nitidulidae). J. Apicul. Res. 54(3), 226-232

SAS Institute. (2009) SAS system for Windows, version 9.4.SAS Institute, Cary, NC

Schmolke M.D. (1974) A study of Aethina tumida: the small hive beetle. Project Report, University of Rhodesia, p. 178

Spreafico, M., Eördegh, F.R., Bernardinelli, I., Colombo, M. (2001) First detection of strains of Varroa destructor resistant to coumaphos. Results of laboratory tests and field trials. Apidologie 32, 49-55

Stuhl, C. (2017) Survival and reproduction of small hive beetle (Coleoptera: Nitidulidae) on commercial pollen substitutes. Fla. Entomol. 100(4), 693-697

Suazo, A, Torto, B, Teal, P, Tumlinson, J. (2003) Response of the small hive beetle (Aethina tumida) to honey bee (Apis mellifera) and beehive-produced volatiles. Apidologie 34(6), 525-533

Zawislak, J., (2010) Managing small hive beetles. Cooperative Extension Service, University of Arkansas, US Department of Agriculture, and county governments cooperating

Publisher's note Springer Nature remains neutral with regard to jurisdictional claims in published maps and institutional affiliations. 